\title{
Training graduate students to be teachers
}

D.V. de-Macedo ${ }^{1}$, E. de-Paula ${ }^{1}$ and B.B. Torres 2

\author{
${ }^{1}$ Departamento de Bioquímica, Instituto de Biologia, \\ Universidade Estadual de Campinas, Campinas, SP, Brasil \\ Departamento de Bioquímica, Instituto de Química, \\ Universidade de São Paulo, São Paulo, SP, Brasil
}

\section{Correspondence \\ B.B. Torres \\ Departamento de Bioquímica \\ Instituto de Q uímica, USP \\ Caixa Postal 26077 \\ 05599-970 São Paulo, SP \\ Brasil \\ Fax: + 55-11-815-5579 \\ E-mail: bayardo@ quim.iq.usp.br \\ Research supported by CAPES/PROIN (No. 004/97) and FAEP/UNICAMP (No. 0776/96). Publication supported by FAPESP.}

Received August 28, 1998 Accepted September 1, 1999

\section{Abstract}

Pedagogic education of graduate students, when and where it exists, is restricted to theoretical courses or to the participation of the students as teachers' assistants. This model is essentially reproductive and offers few opportunities for any significant curriculum innovation. To open an opportunity for novelty we have introduced a new approach in "Biochemistry Teaching", a course included in the Biochemistry Graduate Program of the Biochemistry Department (Universidade Estadual de Campinas and Universidade de São Paulo). The content of the course consists of a) choosing the theme, b) selecting and organizing the topics, c) preparing written material, d) establishing the methodological strategies, e) planning the evaluation tools and, finally, f) as teachers, conducting the course as an optional summer course for undergraduate students. During the first semester the graduate students establish general and specific educational objectives, select and organize contents, decide on the instructional strategies and plan evaluation tools. The contents are explored using a wide range of strategies, which include computer-aided instruction, laboratory classes, small group teaching, a few lectures and round table discussions. The graduate students also organize printed class notes to be used by the undergraduate students. Finally, as a group, they teach the summer course. In the three versions already developed, the themes chosen were Biochemistry of Exercise (UNICAMP), Biochemistry of Nutrition (UNICAMP) and Molecular Biology of Plants (USP). In all cases the number of registrations greatly exceeded the number of places and a selection had to be made. The evaluation of the experience by both graduate and undergraduate students was very positive. Graduate students considered this experience to be unique and recommended it to their schoolmates; the undergraduate students benefited from a more flexible curriculum (more options) and gave very high scores to both the courses and the teachers.
Key words

- Pedagogic training

- Tertiary-level education $\ldots \ldots \ldots \ldots \ldots \ldots \ldots$ 


\section{Introduction}

The lack of formal teacher training faced by graduate students whenever they deal with a teaching situation is widely recognized and constitutes one of their most common criticisms of their own education. Some Master's programs include disciplines in the area of education, in which the theoretical principles that should underlie teaching decisions are explored. The contribution of these courses to the education of graduate students is important but not sufficient. In most students' opinion, these courses are essentially theoretical. When they are taught by education professionals, a conflict is frequently created due to the discrepancy between the jargon used by the educators and the usual language of the graduate students in Biochemistry. This discrepancy makes the utilization of pedagogical concepts a difficult task. Thus, the real pedagogic initiation of the tertiary-level teacher normally takes place when, employed by a higher education institution (with teaching or teaching and research obligations), the new professional starts to deal with teaching attributions as his/her main or secondary activity. In their initiation, the new professionals are included in the teaching staff of the institution, gradually acquiring experience and ability in this function. Without formal preparation, the new professionals improve their pedagogic skills during the exercise of their functions, with their inexperience affecting more strongly the first groups of students. However, this is not the most serious aspect of the process. The most serious criticism one can make is that this way of introducing the new teacher to pedagogic activities, far from contributing to the renewal of the educational process through the beginner's fresh new ideas, constitutes an essentially conservative and reproductive model of the pedagogic system. In fact, when the new teachers become engaged in the courses the lack of alternative models pushes them to follow the established curricula, with their preselected contents, their conventional methodologies, and their traditional structure. The center of the problem is not the maintenance of the traditional curriculum itself but rather its acceptance without criticism.

A research center of Biochemistry Teaching attended by teachers and students from the Departments of Biochemistry at UNICAMP and USP has proposed several solutions to attenuate this problem in the area of Biochemistry, promoting the pedagogic education of their graduate students (1). One of these activities consists of the organization and application of an undergraduate discipline by graduate students. Actually, this activity constitutes an optional eight-credit course included in the Master's or Ph.D. program of these departments, denoted Biochemistry Teaching. This discipline tries to reverse the situation described above, with the fundamental objective of offering the graduate students an opportunity to create an original curriculum not based on previous models. This curriculum, to be described below, is created in a practical and operational way, with theoretical pedagogic principles being offered whenever necessary for the process of decision making.

\section{Procedures}

The discipline Biochemistry Teaching is developed in two stages. In the first, during one semester, the graduate students plan an optional undergraduate discipline. In the second stage, the planned course is given to undergraduates during summer vacation. The planning of the course obeys two norms suggested by the coordinators at the first meeting with the graduate students: 1) the discipline to be planned should not repeat the contents explored in basic disciplines of Biochemistry, and 2) the methodological form to be adopted should not obligatorily consist of a sequence of lectures, but should 
be decided according to the specific objectives. The first task of the graduate students is, therefore, to establish the theme of the course. Their choice is free and is based on a consensus reached after discussing possible topics. In the three versions of the courses already presented the themes chosen were Biochemistry of Exercise (UNICAMP), Biochemistry of Nutrition (UNICAMP) and Molecular Biology of Plants (USP) (Table 1).

Three-hour weekly meetings for the organization of the course are scheduled throughout the semester. Initially, the students survey the pertinent content themes related to the subject. The first contribution to the graduate students' education is introduced here because, due to the nature of the proposed theme, they must look for informa- tion from sources different from the textbooks and the journals normally consulted for their research work. These sources are highly diversified, including libraries of other departments, popular science magazines, Internet and non-academic publications.

After selecting the content, the first attempts to plan a teaching sequence are made. For this purpose, the search for a continuum that will channel the flow of its parts is obligatory. Along with this, the first methodological suggestions arise, at this time still quite conventional. As the planning continues, both the selection and the sequence of the contents will undergo significant changes. At this stage, the students' attention is mainly focussed on the logic of the content itself,

Table 1 - Programs of the undergraduate optional courses offered.

Biochemistry of Exercise - UNICAMP, 1997

Muscle Contraction - Software

General Review of Metabolism

Aerobic and Anaerobic Exercises

Lactate and Glucose Determinations. Measurement of Blood Pressure and Heart Rate before and after Exercising

Cholesterol, HDL and Triglyceride Determination

Cramps and Fatigue

Training and Sedentariness

Hemoglobin, 2,3-Bisphosphoglycerate and Succinate-Dehydrogenase Determination

Biochemical Adaptations Induced by Aerobic Exercise

Planning of Diets

Hypertension and Obesity

Muscle Cell Culture

Action of Hormones and Anabolic Steroids

Effect of Exercise on the Immunologic System

Biochemistry of Nutrition - UNICAMP, 1998

Nutrition through Times

General Review of Metabolism

Food Conservation: Effect of Ethylene, Plant Hormones, Modified Atmosphere and Temperature

Pre- and Post-Diet Measurements of Blood Glucose, Urea, Triglycerides and Cholesterol in Different Diet Therapies Nutritional Calculation of Diets

Calculation of Individual Nutritional Parameters

Planning of Individual Diets Using a Software

Nutritional Losses: Food Preparation and Bioavailability

Malnutrition: World and National Situation. Marasmus, Dwarfism and Kwashiorkor

Obesity
Determination of Lean Mass and Body Fat

Critical Analysis of Weight-Loss Diets

Special Feeding: Sports and Diseases

Genetic Improvement of Foods

Food Industrialization

Vitamins and Free-Radicals - Software

Oxidative Stress. Nutrition and Health

Molecular Biology of Plants - USP, 1998

Compared Cytology and Cellular Division

Organization of Plant Genome

B-Chromosomes. Polyploidy, Replication, Transcription and Translation

Regulation of Genetic Expression

Chloroplasts

Mitochondria

Transposons

Stress Adaptations in Plants

Techniques in Molecular Biology

Biotechnology: Agricultural Improvements

$\gamma$-Linoleic Acid Production

Ionic Mercury Reduction

Ripeness Control

Resistance to Bacteria

Resistance to Insects

Biotechnology: Production of Heterologous Proteins

Antibodies

Human Albumin

Enkephalins

Hepatitis B Antigen

Erythropoietin

Transgenic Plants: Ethical Aspects 
with less attention paid to the learning process. Offering the largest possible amount of up-to-date information is also a strong concern. Up to this moment the emphasis of the planning is exclusively centered on the transfer of information, reflecting the strategies of conventional school education. The proposed objectives, the structure of the contents and the intended strategies, in which lectures and conventional practical exercises prevail, are based on the paradigms of Academic Rationalism (2). The support given by the coordinators at this stage consists of aid in the organization of the content, in the clarification of the objectives and in the suggestion of strategies that will allow the attainment of the objectives. As the planning goes on, the graduate students gradually begin to adopt a more cooperative conception of teaching, trying to establish tasks for their future students and programming activities such as problem solving and/or questions to be answered by the students after practical or theoretical exercises. The center of gravity of the planning starts to migrate, therefore, from the teacher's performance to the students' activities. As cooperative methodologies are introduced, the problem of fitting the content to the available time is raised and the programming of a schedule, rather neglected until this moment, starts to receive as much attention as the contents. Actually, the decisions made during this phase are based on topics of fundamental importance which deal with the review of the fundamental objectives of the course being outlined and the selection of those considered to be the most important. In these discussions the students learn about the principle that the methodologies should be selected to fulfill the previously chosen objectives and that, frequently, an option for certain strategies emphasizes certain objectives. In short, certain methodologies are intended to produce learning, including skills and attitudes, while others focus mainly on the transfer of information; the decision to adopt each kind should be subordinated to the objectives.

The organizational work is used for designing problems, outlines, metabolic maps and other supporting materials. In two versions of these courses, the students made the decision to produce software to be used in their disciplines. Thus, they created the programs Muscle Contraction (3) and Free Radicals (4). A method for the primary culture of muscle cells was also standardized (5). This decision and its products have a special meaning. They emerged from the need to use a kind of material considered essential for a specific teaching situation. Thus, this decision is in contrast to the simple selection of the most suitable materials among those already available, reversing the usual tendency of making the courses secondary to the supporting material (books, mainly) when the logic of the planning points to the opposite direction. It is important to emphasize the gain resulting from the production of new material. From a pedagogic point of view, this translates the clarity of the intended objectives and the demand for adequacy of the supporting material; in the general education, it forces the expansion and the deepening of biochemical knowledge.

In parallel to the planning of the course, the graduate students organize course notes to be used by the undergraduate students with texts which have been written especially for the course, tables to be examined or completed, metabolic maps, protocols of experiments, etc. The production of this material constitutes additional training both in terms of the writing of the texts and of general organization. Arranging all the necessary laboratory material, preparing budgets for equipment to be acquired and providing all the other necessary structure for the course are other tasks of the graduate students.

Some weeks before the beginning of the course a general rehearsal is held and all scheduled activities are tested. This procedure is necessary because, although the 
graduate students divide themselves into groups for the research and organization of specific topics of the contents, when they teach the discipline everyone participates in all activities. The course is offered during summer vacation, with a total of $30 \mathrm{~h}$ condensed into one week. Thirty places are offered to those taking the course.

The interest of undergraduate students was significant. The number of registrations exceeded 100 and it was necessary to establish a selection criterion for registration (another attribution of the graduate students). Each discipline was attended by students from different areas: Biology, Physical Education, Pharmacy and Biochemistry, Food Engineering, Nursing, and Medicine.

The continuous evaluation of undergraduate students was based on different criteria. In two of the courses, the students were asked to provide written answers to some questions presented at the end of each class. In the third course, evaluation was based on the examination of projects elaborated by small groups and presented orally to all participants. During the week when the disciplines were taught the graduate students and the coordinators met daily to evaluate the activities performed during the day and to make the last arrangements for the activities of the following day. In the courses for which daily evaluations were planned, questions and exercises were also corrected daily in order to immediately inform the students about their progress.

\section{Evaluation of the courses}

The pedagogic training herein described was evaluated from two different points of view. The opinion of the graduate students about the validity and importance of the pedagogic education provided by the Biochemistry Teaching course was evaluated by the use of a questionnaire (Table 2); additionally their opinions were collected at evaluation meetings and as spontaneous declarations. In contrast, the quality of

Table 2 - Evaluation of the "Biochemistry Teaching" course by the graduate students.

The numbers presented here are the average answers on a scale from 1 to 10 . The questionnaire was answered by $91 \%$ (UNICAMP, 1997), 80\% (UNICAMP, 1998) and 100\% (USP, 1998) of the students.

\begin{tabular}{|c|c|c|c|}
\hline & $\begin{array}{l}\text { UNICAMP } \\
1997\end{array}$ & $\begin{array}{l}\text { UNICAMP } \\
1998\end{array}$ & $\begin{array}{r}\text { USP } \\
1998\end{array}$ \\
\hline 1. The course constituted an important pedagogic experience. & 9.2 & 9.4 & 9.9 \\
\hline 2. The course prepared you to plan other disciplines. & 9.2 & 8.5 & 9.7 \\
\hline 3. The course contributed to your education as a teacher. & 8.7 & 9.3 & 9.7 \\
\hline 4. The course offered you contact with different teaching methodologies. & 9.7 & 9.0 & 9.4 \\
\hline 5. The course helped you to establish a good relationship with the students. & 9.0 & 9.1 & 9.1 \\
\hline $\begin{array}{l}\text { 6. The course prepared you to organize support material (manuals, } \\
\text { equipment, and general infrastructure). }\end{array}$ & 7.9 & 9.1 & 9.3 \\
\hline 7. The course motivated you for teaching activities. & 8.4 & 9.3 & 9.7 \\
\hline $\begin{array}{l}\text { 8. The course aided you to seek information in sources different from } \\
\text { the customarily consulted books and periodicals. }\end{array}$ & 8.5 & 9.1 & 9.4 \\
\hline $\begin{array}{l}\text { 9. The conduction of the course (going out from the zero and counting with } \\
\text { the teachers' support) was adequate. }\end{array}$ & 8.3 & 8.9 & 9.0 \\
\hline 10. Planning the course was a pleasant activity. & 8.0 & 9.0 & 9.4 \\
\hline 11. Giving the planned course was a pleasant activity. & 8.9 & 9.6 & 9.9 \\
\hline 12. The course contributed to expanding your knowledge of Biochemistry. & 7.7 & 10.0 & 9.4 \\
\hline 13. Do you find this an important experience for graduate students? & 9.1 & 9.6 & 9.7 \\
\hline 14. Would you advise your colleagues to participate in similar experiences? & 9.1 & 9.4 & 9.7 \\
\hline
\end{tabular}


the course they planned and applied and their performance as teachers was determined using the standard questionnaires employed in the Departments of Biochemistry at UNICAMP and USP for the evaluation of their regular courses, answered by the undergraduate students who attended the optional courses (Tables 3 and 4).

The necessity for renewal of the educational strategies at the Universities, stimulated, among other factors, by the speed of changes in the way information is transferred and by the change in the expected skills of future professionals, has been pointed out in diverse discussion forums on the subject and has been the theme of countless publications in specialized journals (6-9), books (10) and in a special section of Science (11). The common guideline suggested by all these publications, which could be achieved by different procedures, is the necessity of transferring the paradigm of the University courses from teaching to learning, with emphasis on attitudes and abilities in addition to mere knowledge. These transformations need, of course, to be preceded by a review of the concept of teaching on the part of the University faculty members. Even though they are not expected to become specialists in Education, it is

Table 3 - Evaluation of the courses "Biochemistry of Exercise" (1997) and "Biochemistry of Nutrition" (1998) given at UNICAMP.

The numbers are the average of the answers, in a scale from 1 to 5 . The questionnaire was answered by $87 \%$ of the undergraduate students in 1997 and by $73 \%$ in 1998. The teachers' evaluation expresses the average score attributed to the graduate students.

1997

1998

Evaluation of the course

1. Execution of the program

2. Appropriateness of the bibliography

3. Appropriateness of the sequence of classes

4. Overlapping of subjects with other courses

5. Coherence between the contents and evaluation

6. Previous presentation of the criteria and forms of evaluation

7. Appropriateness of the required homework

8. Appropriateness of the teaching methodology

9. Evaluation of the course as a whole

Self-evaluation

10. Acquired knowledge

11. Participation in class

12. Execution of tasks and projects

13. Interest of the course for your education

14. Relationship between expectation and reality

Evaluation of teachers

15. Quality of the classes

16. Clarity of the explanations

17. Clarity of the answers to the formulated questions

18. Receptivity to the participation of the students

19. Incentive for the development of criticism

20. Concem about the objectives of the course

21. Punctuality

22. Readiness for homework attendance

23. Evaluation of the teacher's performance as a whole

\section{8}

4.8

4.8

2.5

5.0

4.8

4.8

4.8

4.7

4.8

3.9

4.8

4.7

4.7

4.5

4.6

4.6

4.8

4.6

4.8

4.5

4.9

4.7 
desirable that they exercise their occupation in a more reflective and consequent way, since the training of the new generations depends greatly on this.

The objective of the experiment described here was to establish clear objectives and to search for the best strategy to produce learning in addition to revising the content of Biochemistry courses in a rigorous manner (12). The graduate students consider this type of activity to be important for their education and they strongly advise their colleagues to take part in experiments similar to these (items 13 and 14 in Table 2). Their opinions (13) and behavior reveal that an experiment like this, when well conducted, can be fully satisfactory (Table 2). In the first version of the Biochemistry Teaching course at UNICAMP, the number of registrations greatly exceeded the number of vacancies; the graduate students then decided to repeat the course in order to permit all students to participate. A similar situation occurred at USP where the students intend to repeat the discipline they planned during the subsequent summer. Very high scores were attributed to the performance of the graduate students as teachers, a fact revealing their competence and preparation. The level of their performance is demonstrated when their scores are compared to the scores attributed to the professors of the Biochemistry Departments at UNICAMP (Figure 1) and USP (Figure 2). According to the criteria used by the Institute of Biology at UNICAMP, their score as teachers was 4.7 in 1997 and 1998, comparable to that assigned to $8.3 \%$ of the department teachers with the highest evaluation, and according to the criteria used by the Department of Biochemistry, USP, their score as teachers was 9.1, comparable to that assigned to $8.9 \%$ of the teachers with the best evaluation. The disciplines they have taught were equally successful. At UNICAMP, the disciplines obtained a score of 4.7 (both in 1997 and 1998), comparable to that assigned to $8.3 \%$ of those with the best evaluation
Table 4 - Evaluation of the course “Molecular Biology of Plants" (1998), given at USP.

The questionnaire was answered by $94.1 \%$ of the undergraduate students. The teachers' evaluation expresses the average score attributed to the graduate students.

\begin{tabular}{lr}
\hline & Score \\
\hline General organization & \\
1. Were you informed about the program of the course? & 9.3 \\
2. Did you receive the calendar of activities of the course? & 10.0 \\
3. What percentage of the program was executed? & 9.7 \\
4. Was the duration of the program compatible with the time available? & 7.7 \\
5. Was the amount of homework assigned adequate? & 9.4 \\
6. Was your previous knowledge sufficient to follow the course? & 8.7 \\
Methodology & \\
7. Theoretical class & 8.2 \\
8. Laboratory & 8.3 \\
9. Seminar & 8.6 \\
10. Discussion groups & 8.7 \\
Result of the course & \\
11. Did this course increase your knowledge of relevant information & 9.1 \\
12. Are you convinced that the course is useful for your training? & 9.4 \\
13. Give a grade to the course & 8.7 \\
Evaluation of teachers & \\
14. Punctuality & 9.5 \\
15. Knowledge of the contents & 9.0 \\
16. Clarity in the explanations & 8.9 \\
17. Receptivity to questions & 9.6 \\
18. Incentive to your thinking and criticism & 8.8 \\
19. Incentive to your participation \\
20. Evaluation of the teacher's performance as a whole & 8.9 \\
\hline
\end{tabular}

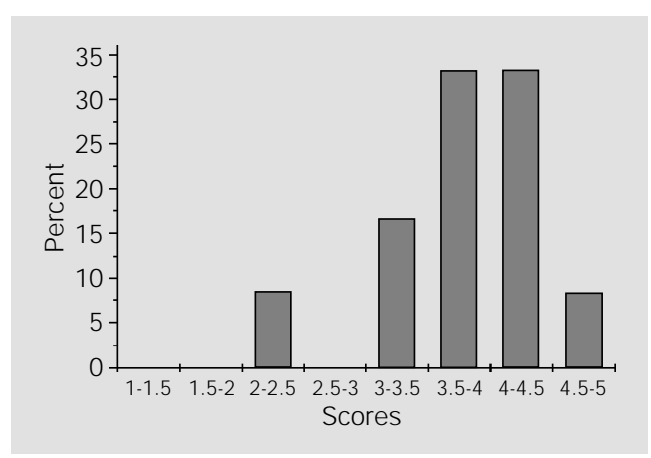

Figure 1 - Scores attributed by the students to the teachers of the Department of Biochemistry (UNICAMP), 1997, on a scale from 1 to 5 (Source: Undergraduate Disciplines Committee - Institute of Biology, UNICAMP).

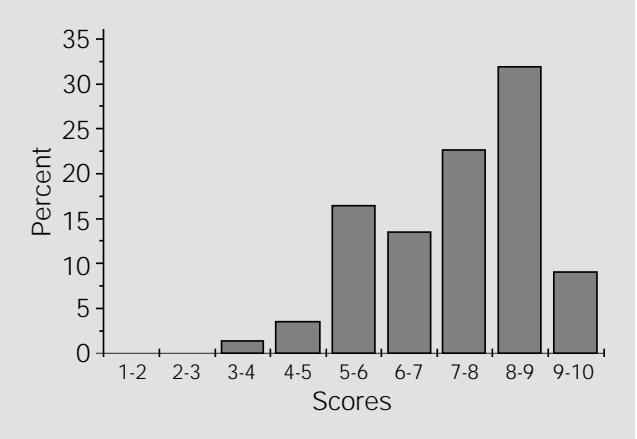

Figure 2 - Scores attributed by the students to the teachers of the Department of Biochemistry (USP), 1996, on a scale from 1 to 10 (Source: Undergraduate Disciplines Committee - Department of Biochemistry, USP) 

the students to the Disciplines of the Department of Biochemistry (UNICAMP), 1997, on a scale from 1 to 5 (Source: Undergraduate Disciplines Committee - Institute of Biology, UNICAMP).
Figure 3 - Scores attributed by

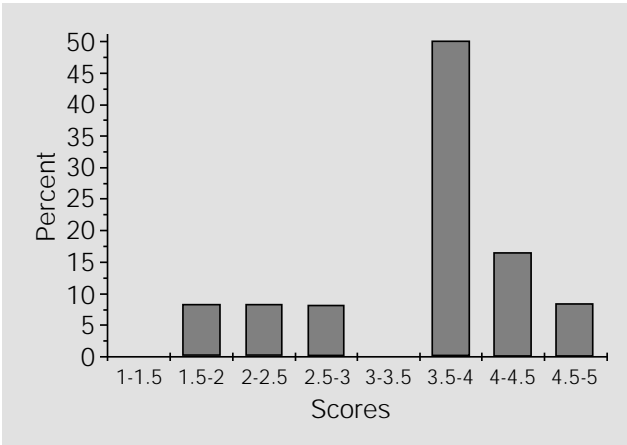

Figure 4 - Scores attributed by the students to the disciplines of the Department of Biochemistry (USP), 1996, on a scale from 1 to 10 (Source: Undergraduate Disciplines Committee - Department of Biochemistry, USP).

Table 5 - Number of participants in the summer courses.

\begin{tabular}{lcrr}
\hline & $\begin{array}{c}\text { UNICAMP } \\
1997\end{array}$ & $\begin{array}{r}\text { UNICAMP } \\
1998\end{array}$ & $\begin{array}{r}\text { USP } \\
1998\end{array}$ \\
\hline $\begin{array}{l}\text { Graduate students } \\
\begin{array}{l}\text { Total number of undergraduate students } \\
\text { enrolled in the regular University Biochemistry courses }\end{array}\end{array}$ & 97 & 110 & 103 \\
$\begin{array}{l}\text { Number of undergraduate students who participated } \\
\text { in the optional summer courses }\end{array}$ & 60 & 30 & 34 \\
\end{tabular}

(Figure 3), and at USP, the discipline obtained a score of 9.0, being located among the best $9.4 \%$ (Figure 4).

The evaluation of summer and regular courses should be carefully compared even if the same questionnaire is used. Students attending different types of disciplines are certainly in different psychological situations. When enrolled in optional summer disciplines students are highly motivated, which might not be the case when they attend regular courses. On the other hand, and for the same reasons, they expect much more from the courses. Nevertheless, they attributed a score of 4.7 , on a 1-5 scale, to the item that measures the expectancy/reality ratio for the disciplines (item 14 in Table 3).

The undergraduate students also benefit from summer courses. Perhaps because of the inflexibility of their curricula, the possibility of complementing their education through disciplines that explore topics of interest for their professional qualification is attractive, and the search for the optional courses has been very expressive (Table 5). The expectation for the continuation of the program is to produce a set of optional disciplines to be offered to undergraduate students. [New disciplines, namely Biochemistry of Water (UNICAMP), Biochemistry of Mind (USP) and Biochemistry and Diseases (USP), took place in January 1999 and Biochemistry of Drugs (UNICAMP) and Experimental Tools in Biochemistry (USP) are scheduled for January 2000].

\section{References}

1. Torres BB (1998). Atividades de ensino dos estudantes de pós-graduação. XXVII Annual Meeting of the Brazilian Biochemistry and Molecular Biology Society (SBBq), May 23-26, Caxambu, MG, Brazil. Round-Table, Abstract MR26-1, XXI.

2. Eisner E \& Vallance E (1974). Conflicting Conceptions of Curriculum. McCutchan Publishing Corporation, Berkeley, CA.

3. Galembeck E, Macedo DV \& Torres BB (1997). Estrutura do músculo esquelético e mecanismo de contração: Um software. XII Annual Meeting of the Brazilian Federation of Experimental Biology Society (FESBE), August 27-30, Caxambu, MG, Brazil.

4. Yokaichiya DK, Galembeck E \& Torres BB (1998). Oxygen free radicals: An introductory software. XXVII Annual Meeting of the Brazilian Biochemistry and Molecular Biology Society (SBBq), May 23-26, Caxambu, MG, Brazil, Abstract J -8, 92.
5. Rodriguez J A, Maria SS \& Melo PS (1997) Muscular primary culture cell standardization as a tool to evaluate effects of anabolic steroid drugs. Brazilian J ournal of Morphological Sciences, 14: 159.

6. Neufeld VR \& Barrows HS (1974). The "McMaster philosophy": an approach to medical education. J ournal of Medical Education, 49: 1040-1050.

7. Neufeld VR, Norman GR, Feightner J W \& Barrows HS (1981). Clinical problem-solv- 
ing by medical students: a cross sectional and longitudinal analysis. Medical Education, 15: 315-322.

8. Vella $F$ (1997). Biochemistry teaching in integrated curricula. Biochemical Education, 25: 75-77.

9. Vella $F$ (1989). Teaching biochemistry for the 21st century. Biochemical Education, 17: 6-8.
10. Longworth N \& Davies WK (1996). Lifelong Learning. Kogan Page, London.

11. Innovations on Campus (1994). Science, 266: 843-893.

12. Macedo DV, de Paula E \& Torres BB (1997). Pedagogic training of graduate students. XXVI Annual Meeting of the Brazilian Biochemistry and Molecular Biology Society (SBBq), May 3-7, Caxambu, MG,
Brazil, Abstract J -4, 83.

13. Silva LP (1998). Planejamento e aplicação de cursos optativos de graduação por pósgraduandos. Graduation-Undergraduation Integration through the Teaching (RoundTable). XXVII Annual Meeting of the Brazilian Biochemistry and Molecular Biology Society (SBBq), May 23-26, Caxambu, MG, Brazil, Abstract MR26-3, XXI. 